\title{
Regulation of Corticotropin-Releasing Factor-Binding Protein Expression in Amygdalar Neuronal Cultures
}

\author{
J. W. Kasckow, ${ }^{* \dagger+}$ A. Regmi, $\uparrow$ A. F. Seasholtz $\$$ and J. J. Mulchahey*† \\ *Cincinnati VAMC; Psychiatry Service, Cincinnati, OH, USA. \\ †University of Cincinnati School of Medicine, Department of Psychiatry, Cincinnati, OH, USA. \\ fUniversity of Cincinnati Neurosciences Program, Cincinnati, OH, USA. \\ $\S$ Department of Biological Chemistry, The University of Michigan, Ann Arbor, MI, USA. \\ IThe Mental Health Research Institute, The University of Michigan. Ann Arbor, MI, USA.
}

Key words: amygdala, corticotropin-releasing factor-binding protein, cultures, steroids.

\begin{abstract}
Corticotropin-releasing factor-binding protein (CRF-BP) is known to regulate the bioavailability of CRF and may also play a role in stress behaviours. CRF-BP has been localized in the pituitary as well as central nervous system (CNS) limbic and cortical areas, including the amygdala. The signal transduction pathways which regulate amygdalar CRF-BP are not well understood. In this report, we have examined the effect of protein kinase $A$ and $C$ activators, CRF, dexamethasone and interleukin-6 (IL6) on CRF-BP mRNA and protein expression in dissociated fetal amygdalar cultures. CRF-BP mRNA levels were determined by Northern analysis following $12 \mathrm{~h}$ treatment with the following agents: forskolin (1-30 $\mathrm{MM})$, CRF (1-1000 nM), phorbol-12-myristate-13-acetate (TPA; 1-50 nM), dexamethasone (1-100 nM) and IL6 (10-500 pM). Significant increases in CRF-BP mRNA were observed in response to forskolin (30 mM), CRF (100, $1000 \mathrm{nM})$, IL6 (100, 500 pM), TPA (50 nM) and dexamethasone (100 nM; $\mathrm{P}<0.05$ for all; $n=3-6$ for all). We extended our observations of CRF-BP expression to the protein level by performing semiquantitative Western analysis of total cellular protein after treatment with the same agents. Twenty-four hour treatment with $30 \mu \mathrm{M}$ forskolin, $1000 \mathrm{nM}$ CRF, $50 \mathrm{nM}$ TPA, $100 \mathrm{pM}$ IL6 or $100 \mathrm{nM}$ dexamethasone significantly increased CRF-BP expression $(\mathrm{P}<0.05, \mathrm{n}=3$ for each treatment). The primary cultures were then transfected with a rat CRF-BP-reporter construct containing 3500 base pairs of CRF-BP $5^{\prime}$ flanking DNA.

Treatment with all five agents produced statistically significant increases above control $(P<0.05$; $\mathrm{n}=3$ for each). The results suggest that CRF-BP in the amygdala is stimulated by numerous pathways which may play a significant role in promoting behavioural changes.
\end{abstract}

Corticotropin-releasing factor (CRF) is a neuropeptide which has been isolated from various species including the sheep, rat, mouse and human (1). CRF is distributed heterogeneously throughout the central nervous system (CNS); it is also found in placental tissue and other peripheral tissues as well, including the adrenal medulla and testes (2). CRF co-ordinates the neuroendocrine, behavioural, autonomic and immune responses to stress (2). There is a body of evidence which supports an important role for amygdalar CRF in the mediation of stress-like behaviours. Amygdalofugal pathways have been documented to participate in autonomic, endocrine and behavioural responses to stressors (3). CRF neurones densely innervate the central nucleus of the amygdala and injection of CRF into this region leads to the expression of numerous stress-like behaviours (4).

The CRF-binding protein (CRF-BP) is a $37-\mathrm{kDa}$ protein first isolated from human plasma by CRF affinity chromatography (5) which was subsequently sequenced and cloned. CRF binds to the CRF-BP with an affinity higher than that of the CRF receptor $\left(K_{\mathrm{i}}=0.4\right.$ and $1.7 \mathrm{nM}$, respectively; $\left.6-8\right)$. CRF-BP has been localized to corticotropic cells of the anterior pituitary, where it is thought to regulate $\mathrm{ACTH}$

Correspondence to: J.W. Kasckow, University Cincinnati School of Medicine, Department of Psychiatry, 231 Bethesda Avenue (ML 559), Cincinnati, OH 45267-0559, USA.

Reprint requests: J.W. Kasckow, Cincinnati VAMC, Psychiatry Service (116A), 3200 Vine Street, Cincinnati, OH 45220, USA (e-mail: Jkasckow@pol.net).

(C) 1999 Blackwell Science Ltd 
secretion by binding to CRF and inhibiting its ACTH releasing activity (9). This has been demonstrated in rat primary pituitary cultures (8) as well as in cultured mouse anterior pituitary cells (7).

It has been hypothesized that CRF-BP levels may modulate the HPA axis in response to stress. Following restraint stress, steady state levels of pituitary CRF-BP mRNA increase 2-3 times over basal levels of expression for up to $2 \mathrm{~h}$ after the restraint (10). CRF-BP has also been detected in numerous limbic regions, including the amygdala (9). Although the function of CRF-BP in the amygdala is not known, CRF-BP and CRF are colocalized at the cellular level in the amygdala. It is possible that the CRF-BP may regulate CRF's actions in the amygdala like that in the pituitary.

In this report we seek to further our understanding of the cellular regulation of CRF-BP expression in the amygdala by utilising primary amygdalar cultures. Determination of the signal transduction pathways responsible for amygdalar CRF-BP expression would help investigators better understand what role limbic CRF-BP plays in the mediation of stress behaviours. We have examined the cellular actions of CRF on CRF-BP mRNA and protein expression with activators of the protein kinase $\mathrm{A}$ and protein kinase $\mathrm{C}$ pathway, the cytokine interleukin-6 and dexamethasone. Since all agents increased expression, we have also transfected primary amygdalar cultures with a reporter construct containing 3500 base pairs of the 5' regulatory region of the CRF-BP gene with the above stimuli in order to determine whether this gene region accounts for the observed alterations in CRF-BP expression.

\section{Materials and methods}

\section{Preparation of primary amygdalar cultures}

Amygdalar neuronal culture methods were based on Brouard et al. (11), Cratty and Birkle (12) and Kasckow et al. (13). The procedures were approved by the University of Cincinnati Animal Use Committee. Pregnant Sprague Dawley rats (Harlan, Indianapolis, IN, USA), containing embryonic day 19 pups were killed by administration of $\mathrm{CO}_{2}$. The uterus was placed in phosphate buffered saline (PBS: $\mathrm{NaCl}, 137 \mathrm{mM} ; \mathrm{Na}_{2} \mathrm{HPO}_{4}, 21 \mathrm{mM} ; \mathrm{KH}_{2} \mathrm{PO}_{4}$, $29 \mathrm{mM}$; KCl, $1.2 \mathrm{mM}$; $\mathrm{pH} 7.3$ ) and the embryos were removed and decapitated. Following this, the brain was removed and after slicing away the brainstem, the remainder of the brain was placed ventral side up. A coronal cut was made posterior to the optic chiasm and anterior to the diencephalon in order to remove the frontal cortical region. A diagonal cut was then made along the lateral fissure and the amygdaloid region was separated by gently peeling away the cortex.

Brain slices were placed in PBS. Cells were dissociated for $10-15 \mathrm{~min}$ at $37^{\circ} \mathrm{C}$ in $0.25 \%$ trypsin containing 75 units $/ \mathrm{ml}$ of DNAse I in serum-free medium (SFM) consisting of a mixture of Dulbecco's modified essential medium and Ham's F-12(1:1, v/v from Gibco, St Louis, MO, USA) supplemented with $14 \mathrm{mM}$ glucose, $15 \mathrm{mM} \mathrm{NaHCO}$, $5 \mathrm{mM}$ Hepes and $0.05 \mathrm{U} / \mathrm{ml}$ of penicillin-streptomycin (Sigma, Gaithersburg, MD, USA). Cells were collected by centrifugation $(500 \times \mathrm{g}, 5 \mathrm{~min})$, resuspended in SFM supplemented with $7.5 \%$ foetal calf serum (Atlanta Biologicals, Norcross, GA, USA). For analysis of CRF-BP peptide and mRNA, cells were plated at a density of 3.5 million cells $/ 100 \mathrm{~mm}$ tissue culture dishes (Falcon, Franklin Lakes, NJ, USA). For microscopic analysis, cells were grown in 8-well LabTek II Chamber Slide Systems at 75000 cells per well (Nalge Nunc International, Naperville, IL, USA).

We coated the plates with gelatin $(250 \mathrm{mg} / \mathrm{ml}, 30 \mathrm{~min}$, room temperature; Sigma) and polyornithine ( $\mathrm{MW}=40000 ; 1.5 \mathrm{mg} / \mathrm{ml}$, overnight at room temperature; Sigma) based on Brouard et al. (11). Following plating, cells were incubated at $37^{\circ} \mathrm{C}$ in a $95 \% \mathrm{O}_{2} / 5 \% \mathrm{CO}_{2}$ atmosphere. Medium was totally removed at day 5 and replaced by fresh medium containing cytosine arabinoside (AraC; $20 \mathrm{mM}$ ) to limit the proliferation of glial cells (14).

Immunocytochemistry

The ABC method using a VectaStain kit (Vector Labs, Burlingame, CA, USA) was utilized using a rabbit antibody to CRF-BP (provided by W. Vale, PhD, Salk Institute, La Jolla, CA, USA). Protocols from Vector Labs were utilised. Tissue was incubated initially with normal goat serum with $2 \%$ bovine serum albumin (BSA) for $30 \mathrm{~min}$ at room temperature to block nonspecific binding and then incubated with the CRF-BP antibody $(1: 2000)$ overnight at $4{ }^{\circ} \mathrm{C}$. This was followed by a 30 -min incubation at $4{ }^{\circ} \mathrm{C}$ with biotinylated IgG (Vector Laboratories, Burlingame, CA, USA) and then with the ABC complex (Vectastain Elite ABC Kit, Vector Labs). The cultures were then incubated with the substrate-diaminobenzidine $/ \mathrm{H}_{2} \mathrm{O}_{2}$ (DA substrate $\mathrm{Kit}$, Vector Labs) at room temperature for 2-10 min. Cultures were photographed with a Leitz Ortholux microscope interfaced with a Leica Wild MPS52 camera.

\section{Stimulation experiments}

Cells were washed with SFM. Test substances were then added in an incubation medium consisting of $\beta$-Pit Julip $+0.1 \%$ BSA, based on Vale et al. (15). For the final CRF-BP mRNA analysis, cultures were incubated for $12 \mathrm{~h}$ and for CRF-BP analysis cultures were incubated for $24 \mathrm{~h}$. The following test substances at the following concentrations were utilized: CRF (Peninsula Laboratories, Inc., Belmont, CT, USA; 1, 10, 100, $1000 \mathrm{nM}$ ), forskolin (Sigma; 0, 1, 3, 10, $30 \mathrm{mM}$ ), the phorbol ester-phorbol 12 myristate 13-acetate (TPA; Sigma; 0, 1, 20, $50 \mathrm{nM}$ ), interleukin-6 (IL6; Promega, Madison, WI, USA; $0,10,50,100,500 \mathrm{pM}$ ) and dexamethasone (Sigma; 0, 1, 10, 50, $100 \mathrm{nM}$ ). For mRNA analysis, we initially treated cultures with the highest dose of each stimuli for $6,9,12,18$ or $24 \mathrm{~h}$ and then chose the optimal time for performing concentration-response studies. Each experiment was replicated at least twice and each experiment was derived from a different preparation of primary cultures.

\section{CRF-BP $m R N A$ detection by Northern hybridization}

Total RNA from cells was isolated using the TRIzol reagent (Research Products International, Cincinnati, OH, USA). Twenty $\mu$ g total RNA per lane was electrophoresed in an agarose-formaldehyde gel $(1.2 \% / 2.2 \mathrm{M})$ for $2 \mathrm{~h}$ at $80 \mathrm{~V}$ as previously described (16). RNA was transferred to a Hybond-N nylon membrane (Amersham, Arlington Heights, IL, USA; $2^{\circ} \mathrm{C}$ overnight at $0.25 \mathrm{~mA}$ ) and cross-linked to the membrane with a Stratalinker $1800 \mathrm{UV}$ crosslinker (Stratagene, La Jolla, CA, USA). The Northern Blot was prehybridized in ExpressHyb hybridization solution (Clonetech, Palo Alto, CA, USA) for $30 \mathrm{~min}$ at $65^{\circ} \mathrm{C}$. A 32P-labelled cDNA probe for CRF-BP was generated with a PrimeIt-II oligonucleotide kit (Stratagene). The CRF-BP probe was generated using a 500-bp PstI fragment from a pBluescript SK construct provided by Dr W. Vale (Salk Institute, La Jolla, CA, USA). The blot was then hybridized at $65^{\circ} \mathrm{C}$ with $1 \times 106$ c.p.m. $/ \mathrm{ml}$ labelled probe in ExpressHyb hybridization solution for $1 \mathrm{~h}$. After washing, the membrane was exposed to Xomatic film (Kodak, Rochester, NY, USA) for 24-48 h and developed. A Foto/Eclipse Imager (Fotodyne Inc., Hartland, WI, USA) interfaced with a Power Macintosh 8100/110 using NIH ImageQuant analysis software was utilized for densitometric quantification of the mRNA bands. Quantifications were done within the linear range of the film.

\section{CRF-BP determination by Western blot}

Cells were lysed in $25 \mathrm{mM}$ Tris buffer ( $\mathrm{pH} 8.8$ ) containing $192 \mathrm{mM}$ glycine, $0.1 \%$ SDS, and $0.5 \mathrm{mM}$ phenylmethylsulphonyl fluoride. Eighty $\mathrm{mg}$ of the lysate was electrophoresed in a $10 \%$ acrylamide gel containing $0.4 \%$ SDS and $0.5 \mathrm{M}$ Trizma, $\mathrm{pH} 8.8$ at $100 \mathrm{~V}$ for $3 \mathrm{~h}$. Protein was transferred to a nitrocellulose membrane (Amersham) overnight at $2{ }^{\circ} \mathrm{C}$ and $25 \mathrm{~V}$. The membrane was incubated with rabbit antihuman CRF-BP $(1: 10000)$ : overnight at $4 ; \mathrm{C}$. After washing, the membrane was incubated with goat antirabbit antibody ( $1: 1000$; Vector). The membrane was washed at room temperature and the immunoreactive protein bands were detected using the enhanced chemiluminescence ECL kit (Amersham). The membrane was exposed to Xomatic film (Kodak) for 2-60 s and then developed. A Foto/Eclipse Imager (Fotodyne, Inc.), interfaced with a Power Macintosh 8100/110 using NIH ImageQuant analysis software, was used for densitometric analysis of band intensity. This was normalized to total protein per lane of loaded lysate. Rainbow markers (Gibco BRL) were used to estimate protein size. Recombinant CRF-BP(25 pg) served as a positive control (provided by Dr Vale). 


\section{Transfection}

Cells were transfected in six well plates (Falcon, Lincoln Park, NJ, USA) with a CRF-BP-chloramphenicol acetyltransferase (CAT) plasmid and treated with the same stimuli utilised above. Cells were transfected at a density of $2 \times 106$ using the Lipofectamine Reagent (Gibco-BRL). The 3,500 CRF-BPCAT plasmid utilized contained a 3500 base pair SacI fragment of the rat CRF-BP gene, $\approx 3500$ base pairs of $5^{\prime}$ flanking DNA and 66 base pairs of $5^{\prime}$ untranslated sequences from exon 1 . This was linked to the promoterless reporter plasmid, pGSVOCAT (18). Four $\mu \mathrm{g}$ of $3500 \mathrm{CRF}-\mathrm{BP}-\mathrm{CAT}$ and $1 \mathrm{mg}$ of pSV-b-galactosidase control vector (Promega) were diluted in OptiMem medium with the Lipofectamine reagent (Gibco-BRL) based on the manufacturer's recommended procedures. DNA solution was then added to the cells and incubated at $37^{\circ} \mathrm{C}$ for $2-3 \mathrm{~h}$. Following a $36-\mathrm{h}$ incubation at $37^{\circ} \mathrm{C}$ in serum containing medium, cells were then treated $15 \mathrm{~h}$ with either $100 \mathrm{nM}$ CRF, $30 \mathrm{mM}$ forskolin, $100 \mathrm{pM}$ IL6 or $50 \mathrm{nM}$ TPA or $8 \mathrm{~h}$ with $100 \mathrm{nM}$ dexamethasone in serum free $\beta$-pit Julip medium containing $0.1 \%$ BSA. After treatment, cells were lysed using $100 \mathrm{ml}$ of $250 \mathrm{mM}$ Tris $\mathrm{pH} 8,0.5 \%$ Triton $\mathrm{X}-100$ and rapidly frozen on dry ice. CAT assay was performed with $80 \mathrm{ml}$ of cell extract using the Quan-T-CAT assay system (Amersham). The pSVb-galactosidase was included to control for differences in transfection efficiency and $\beta$-galactosidase was assayed based on the Promega protocol. Levels of CAT expression were normalized to $\beta$-galactosidase. In addition, as a control we transfected cells with the promoterless reporter plasmid, pGSVOCAT.

\section{Statistical analysis}

The quantitative data obtained were expressed as mean + SEM. Data were subjected to ANOVA followed by Duncan's Multiple Range Test using INSTAT Software (Loyola University Medical Center, Chicago, IL, USA). A P-value $<0.05$ was considered sufficient to reject the null hypothesis.

\section{Results}

\section{Morphology of amygdalar CRF-BP cells in vitro}

Figure 1A illustrates a typical amygdalar culture stained with anti-CRF-BP antibody 17 days following dispersion. Figure 1в represents control staining in which the CRF-BP antibody was replaced by non-immunised rabbit serum. By this time cells grew as monolayers and many cells developed long processes extending from the cell bodies to the neighbouring cells. Cell viability at this stage was $97.8+0.5 \%(\mathrm{n}=$ 4) based on trypan blue exclusion. CRF-BP immunoreactive cells displayed immunoreactive cell bodies, elaborate varicose cell processes and apparent nuclear sparing.

\section{Regulation of CRF-BP $m R N A$ expression in primary amygdalar cultures}

The size of the CRF-BP transcript in these cells was 1.85 kilobases as observable in other systems (data not shown; (8, 19)). Figure 2 depicts changes in CRF-BP mRNA following $12 \mathrm{~h}$ of treatment with various concentrations of CRF. We initially examined time course changes with $1000 \mathrm{nM}$ CRF treatment at 6, 9, 12, 18 and $24 \mathrm{~h}$ (data not shown). The peak CRF-BP mRNA expression following CRF treatment occurred at $12 \mathrm{~h}$. The same was true when other treatments were administered so that this time was chosen to examine concentration-dependent effects of CRF and the other compounds. The autoradiograms in the upper portion of Fig. 2 depicts the CRF-BP mRNA and 28S ribosomal RNA(28S) changes with CRF concentrations of $0,1,10,100$ and $1000 \mathrm{nM}$. The $28 \mathrm{~S}$ blots showed no change in signal as a result of CRF or any subsequent challenge and were used to correct the CRF-BP Northern blot for differences in RNA loading. The histogram in the lower portion of Fig. 2 reveals
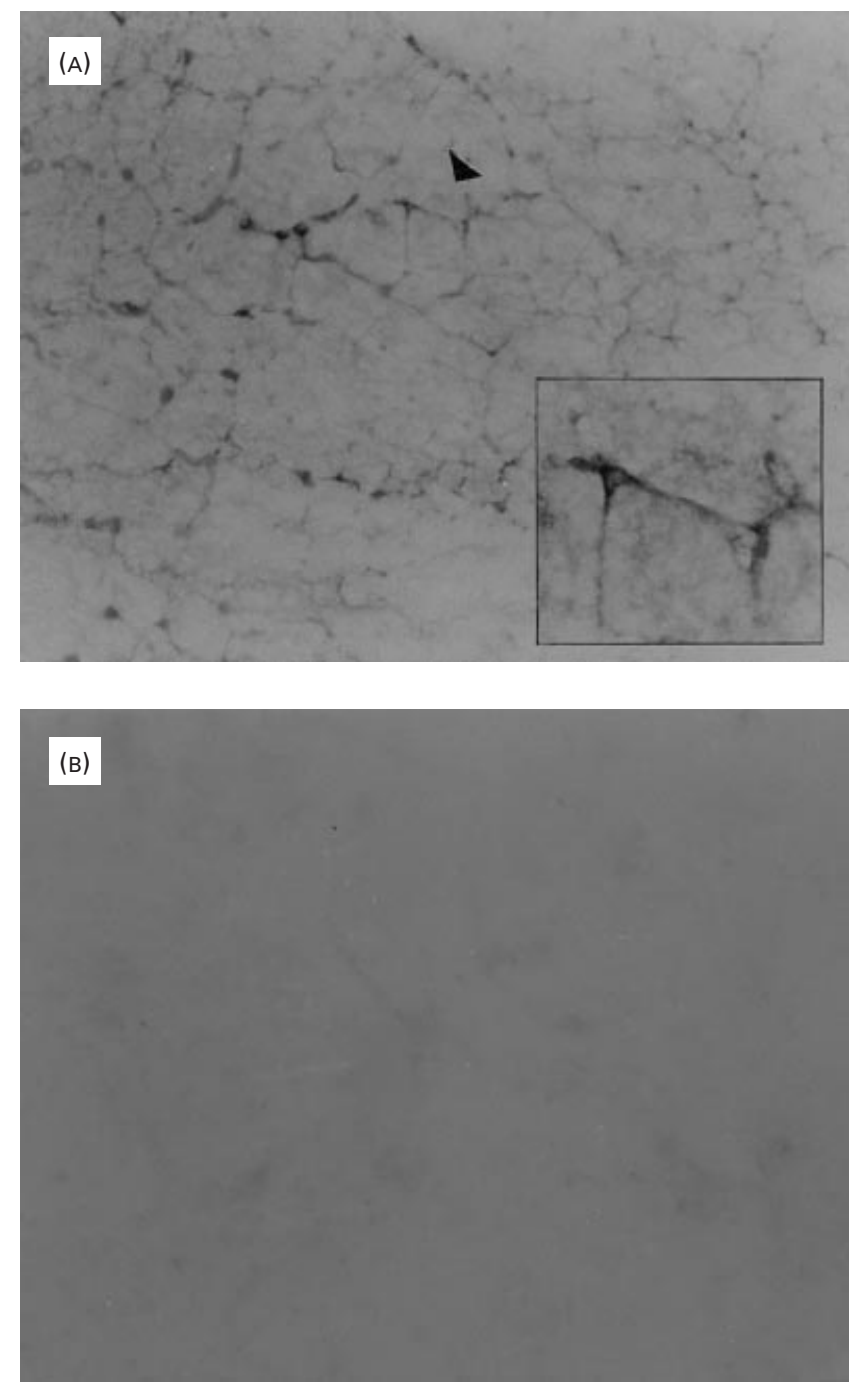

FIG. 1. This photograph demonstrates the primary amygdalar cultures on day 17 stained with (A) anti-CRF-BP antibody or (B) non-immunized rabbit serum based on methods outlined in the text. The insert $(\times 800)$ in (A) depicts one of the cells, designated by an arrow in which one can observe CRF-BP immunoreactivity distributed throughout the cell except for the nucleus. Magnification of (B) and lower power portion of (A), $\times 110$.

the quantitative changes in levels of CRF-BP mRNA with increasing concentrations of $\mathrm{CRF}$ when corrected to $28 \mathrm{~S}$. Concentrations of CRF at 100 and $1000 \mathrm{nM}$ lead to significant increases in CRF-BP mRNA expression $(\mathrm{P}<0.05)$.

Changes in CRF-BP mRNA following $12 \mathrm{~h}$ treatment with various concentrations of TPA, IL6, dexamethasone or forskolin are depicted in Fig. 3. A representative autoradiogram is shown at the top of each figure and depicts the CRF-BP mRNA and $28 \mathrm{~S}$ changes observable in autoradiograms with concentrations of the various agents. The lower portion of each of the figures reveals the quantitative changes in levels of CRF-BP mRNA corrected to $28 \mathrm{~S}$ with increasing concentrations of each agent. Concentrations of the following agents lead to significant increases in CRF-BP mRNA expression $(\mathrm{P}<0.05): 100$ pM IL6, 500 pM IL6, $100 \mathrm{nM}$ DEX, $50 \mathrm{nM}$ TPA and $30 \mu \mathrm{M}$ forskolin. 


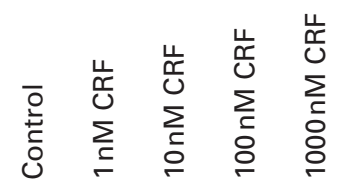
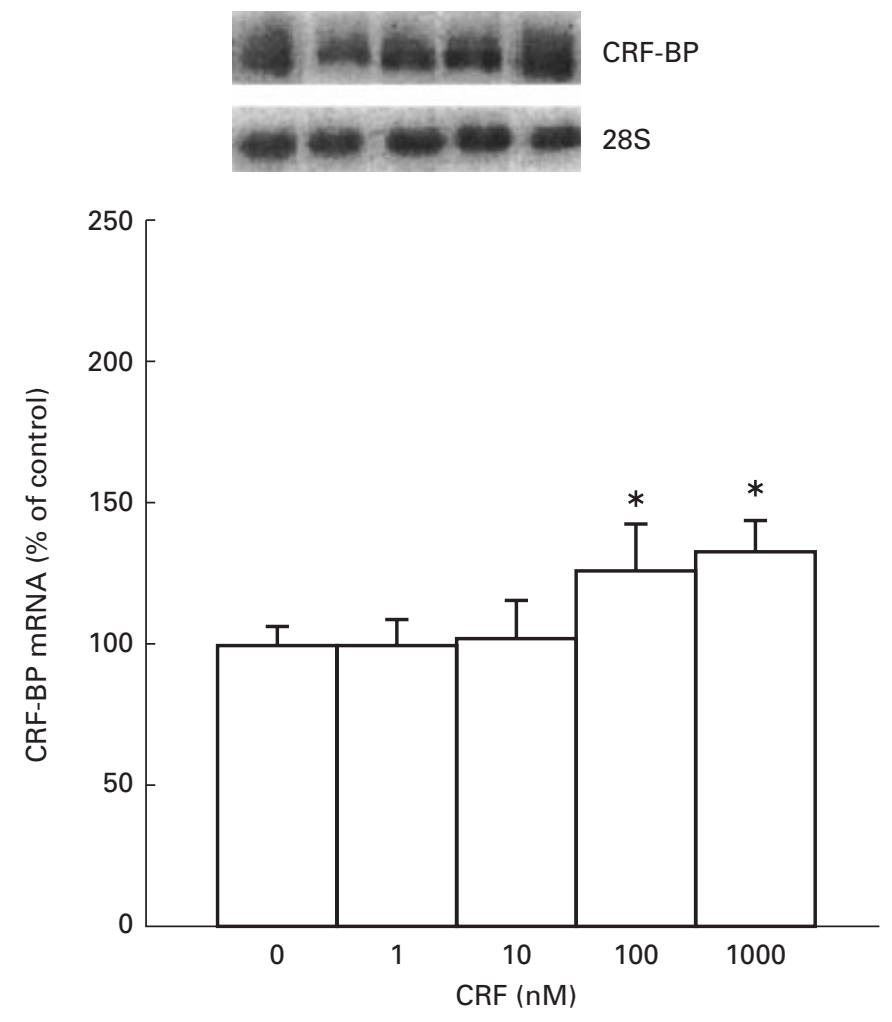

FIG. 2. CRF-BP messenger RNA changes in primary cultures at various $\mathrm{nM}$ concentrations of corticotropin-releasing factor (CRF) following $12 \mathrm{~h}$ of incubation. A representative autoradiogram of the Northern blots probed for CRF-BP messenger RNA or $28 \mathrm{~S}$ ribosomal RNA(28S) expression with increasing concentrations of CRF is shown on the upper portion of the figure. The histogram at the lower region of the figure depicts the densitometric values of each concentration at various time points normalized to untreated controls and corrected for gel loading. Bars represent mean \pm SEM $(n=3-6)$. Statistical significance for each concentration in comparison to control, as determined by anova, followed by Duncan's Multiple Range Test is represented by * for $\mathrm{P}<0.05$. The data were pooled from at least three independent experiments.

\section{Regulation of CRF-BP expression in primary amygdalar cultures}

We questioned whether the expression of CRF-BP was responsive to the same agents which increased CRF-BP mRNA expression. We performed semiquantitative Western analysis of total cellular protein after $24 \mathrm{~h}$ treatment with $30 \mu \mathrm{M}$ forskolin, $100 \mathrm{nM}$ dexamethasone, $100 \mathrm{pM}$ IL6, $50 \mathrm{nM}$ TPA or $100 \mathrm{nM}$ CRF. The results are depicted in Fig. 4. The upper portion of Fig. 4 depicts a representative Western blot with the various treatments. The histogram in Fig. 4 reveals the semiquantitative densitometric analysis obtained with each treatment. Significant increases were observable with all treatments $(\mathrm{P}<0.05 ; \mathrm{n}=3$ for all $)$.
Response of the rat CRF-BP promoter in primary amygdalar cultures to stimuli

Primary cultures were transfected with a CRF-BP reporter construct to determine whether similar patterns of regulation would be observed between transfection assays and endogenous CRF-BP gene expression. The times of incubation were chosen based on preliminary experiments (data not shown) which revealed when maximal increases in expression occurred. The results from the transfection studies are depicted in Fig. 5. Transfections with the rat CRF-BP promoter-CAT construct followed by treatment with all 5 agents produced qualitatively similar results as observed above ( $\mathrm{P}<0.05, \mathrm{n}=3$ for all $)$ suggesting that the DNA sequences required for regulation by CRF, cAMP, TPA, IL6 and dexamethasone are contained within the 3500 base pair of CRF-BP DNA. Transfection of the cultures with a pGSVOCAT construct lacking the 3500 base pair of $5^{\prime}$ flanking DNA yielded levels of CAT expression which were no different from that observed in cells which were not transfected.

\section{Discussion}

Primary amygdalar cultures have been utilised in the past to analyse the actions of stimuli on CRF expression (13). We have now used this experimental model to study the regulation of CRF-BP expression. We first determined that our amygdalar cultures express CRF-BP which is detectable by immunocytochemistry, Western blot and Northern blot analysis. In addition, we have demonstrated that the expression of CRF-BP is regulated insofar as various agents such as CRF, forskolin, dexamethasone, TPA and interleukin-6 (IL6) can increase expression of CRF-BP mRNA and protein and also stimulate CRF-BP promoter activity. All stimuli examined to date increase CRF-BP expression; those which decrease CRF-BP expression remain to be determined.

The quantitative changes in CRF-BP message and protein levels are statistically significant but not dramatic. The modest quantitative increases in CRF-BP mRNA levels observed may reflect our measurement of steady state CRF-BP levels. In addition, there does appear to be a discrepancy with regards to the relative increases in CRF-BP mRNA and CRF-BP levels achieved with forskolin vs dexamethasone. Our Western blots detected higher levels of protein expression with dexamethasone relative to forskolin; with Northern blots, the opposite was true. The reason for this is unknown although relative differences in message or protein stability may be a contributing factor.

The behavioural and physiologic relevance of the small changes in mRNA and protein expression we observed remain to be determined. It is possible that levels of CRF-BP mRNA induction achieved with these agents could have been greater if higher concentrations of stimuli were used in the culture system. The increases in CRF-BP expression observable in our system were, however, comparable to that reported by others following the administration of similar stimuli. For instance, intraventricular injections of IL6 in rats will significantly increase metallothionen-II protein levels to approximately $120 \%$ of baseline (20). In addition, intravenous 

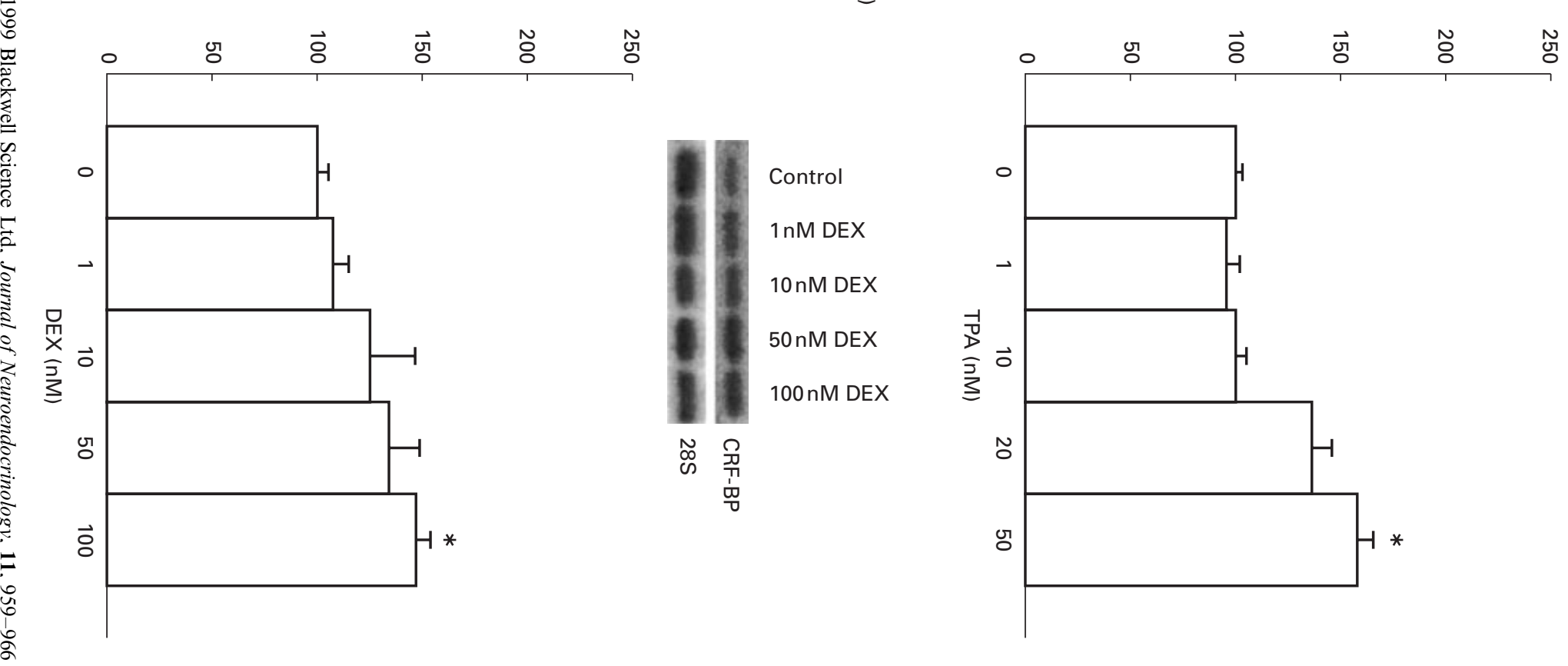

CRF-BP mRNA (\% of control)

可
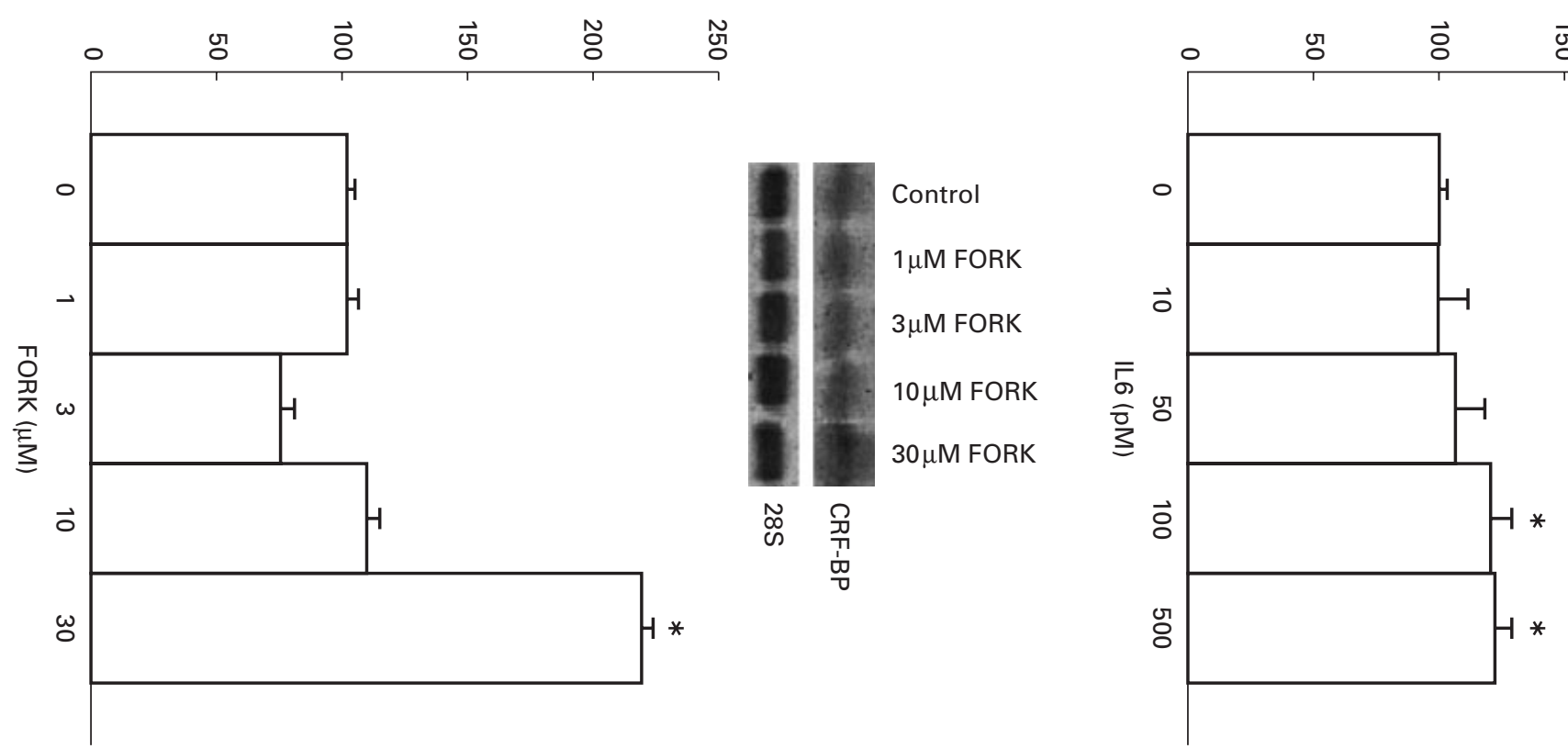


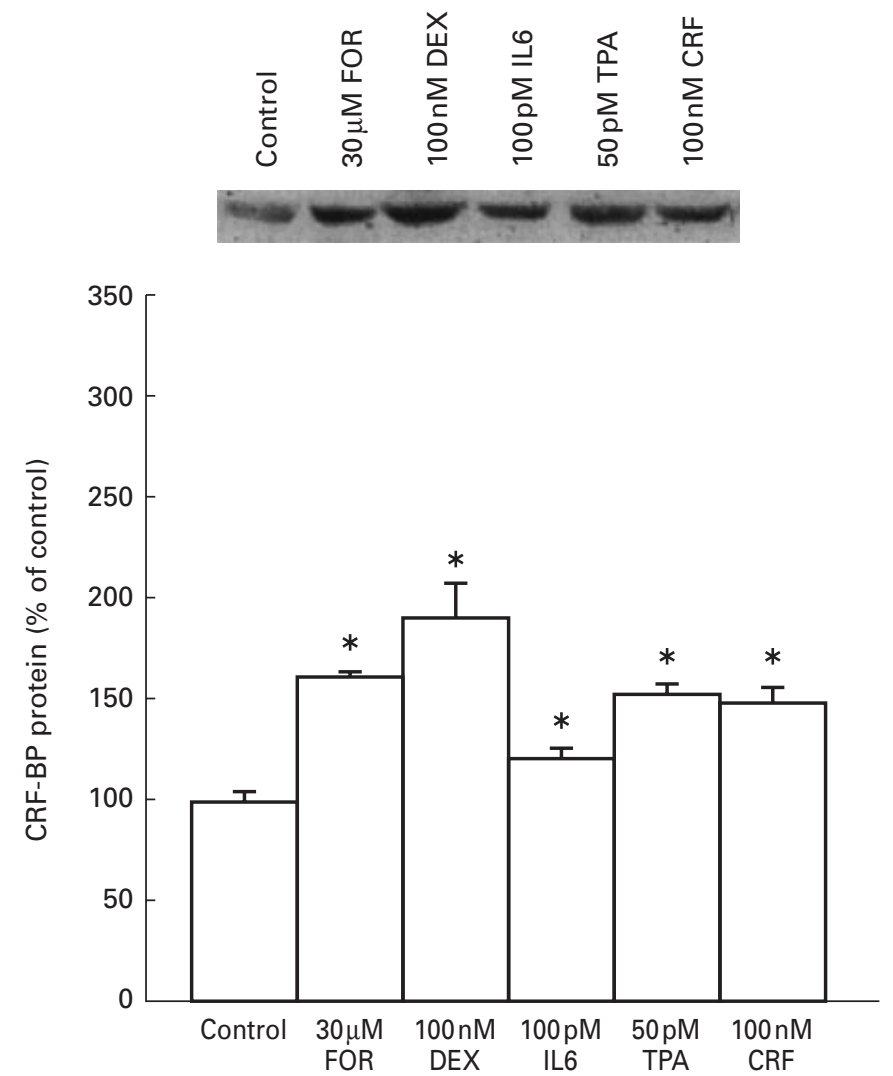

FIG. 4. Semi-quantitative Western analysis of CRF-BP expression relative to control with a variety of stimuli after $24 \mathrm{~h}$ of treatment. The upper portion reveals a representative Western blot of CRF-BP after a variety of treatments at the same concentrations used for semiquantitative analysis. Bars represent mean $\pm \operatorname{SEM}(n=3)$. Statistical significance for each concentration in comparison to control, as determined by ANOVA, followed by Duncan's Multiple Range Test is represented by * for $\mathrm{P}<0.05$. The data were pooled from three independent experiments.

injections of IL6 in rats result in significant $20 \%$ increases in hippocampal 5-HIAA levels relative to control (21).

Cross talk between various signal transduction pathways may occur in the amygdala in vivo and this mechanism may be one way in which the small changes in CRF-BP expression we observed may be amplified with multiple stimuli. For instance, the STAT5 and glucocorticoid receptor pathways are known to interact synergistically to enhance casein gene expression (22). Furthermore, STAT5 is known to play a role in activating the c-fos gene and in this manner, IL-6 and protein kinase C (PKC) pathways may also converge (23). It is also of interest that some agents which increase the expression of CRF in amygdalar cultures also increase the expression of CRF-BP. We had previously demonstrated that forskolin and IL6 will increase CRF expression in dissociated

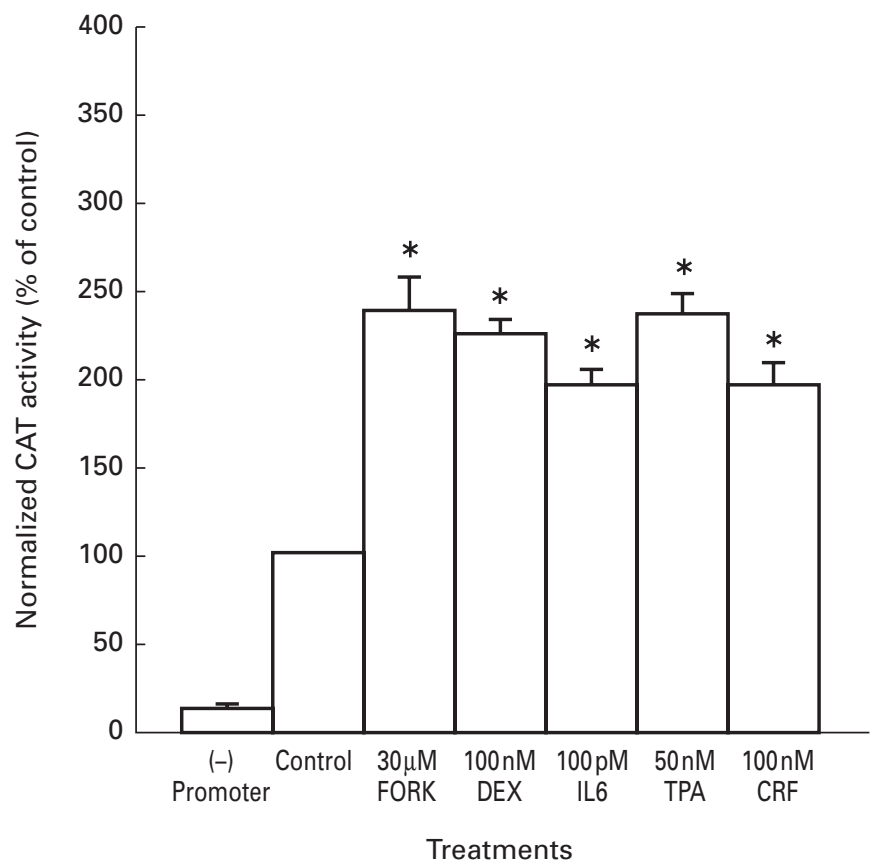

FIG. 5. Four $\mu \mathrm{g}$ of $3500 \mathrm{BP}-\mathrm{CAT}$ was transfected into $2 \times 10^{6}$ cells from primary amygdalar cultures. Cells were treated with $100 \mathrm{nM}$ dexamethasone (DEX) for $8 \mathrm{~h}$ or for $15 \mathrm{~h}$ with the other stimuli. Promoter activity is expressed as percentage of control. Milliunits of CAT have been normalized to milliunits of $\beta$-galactosidase and each bar depicts mean \pm SEM. The figure also depicts the results obtained with a promoterless CAT construct (-promoter). Statistical significance for each concentration in comparison to control, as determined by ANOVA and Duncan's Multiple Range test, is represented by * for $\mathrm{P}<0.05$. The data was pooled from three independent experiments.

amygdalar cultures (13) and the current studies reveal that these agents can also increase the expression of CRF-BP. The net result of such a dual effect would be expected to alter the bioavailability of CRF.

There is evidence from various model systems that agents such as protein kinase activators can modulate CRF-BP expression. In mixed neuronal and pure astrocyte cultures, activators of protein kinase A (PKA) and PKC will increase CRF-BP expression (17). Transfection experiments with CRF-BP reporter constructs in tumour derived cell lines demonstrate positive regulation of the CRF-BP promoter by protein kinase $\mathrm{A}$ and by $\mathrm{CRF}$ in cells expressing the CRFreceptor (18). In an immortalized amygdalar cell line, CRF, forskolin, IL6, TPA and dexamethasone will also stimulate CRF-BP expression. The results from our observations in dissociated amygdalar cultures are entirely consistent with all of these findings and furthermore appear to validate the immortalized amygdalar cell line as a useful model of CRF-BP expression (19).

FIG. 3 CRF-BP messenger RNA changes in primary cultures at various concentrations of: (A) phorbol-12-myristate-13-acetate (TPA); (В) interleukin-6 (IL6); (C) dexamethasone (DEX); or (D) forskolin (FORK) following $12 \mathrm{~h}$ of incubation. A representative autoradiogram of the Northern blots probed for CRF-BP messenger RNA or $28 \mathrm{~S}$ ribosomal RNA(28S) expression with increasing concentrations of each stimuli is shown on top of each histogram. The histogram depicts, for each treatment, the densitometric values of each concentration at various time points normalized to untreated controls and corrected for gel loading. Bars represent mean \pm SEM $(n=3-6)$. Statistical significance for each concentration in comparison to control, as determined by ANOVA, followed by Duncan's Multiple Range Test is represented by $*$ for $\mathrm{P}<0.05$. The data were pooled from at least three independent experiments. 
In contrast, the responses of CRF and CRF-BP to dexamethasone are distinct in the dissociated amygdalar cultures. Previously we reported a lack of response of CRF mRNA in dissociated amygdalar cultures to dexamethasone (13). In addition, in those experiments, dexamethasone was not able to alter the stimulated response of the CRF peptide achieved with forskolin or IL6. The lack of a CRF response to dexamethasone in these amygdalar cultures contrasts with the consistent decreases of CRF levels demonstrable in the hypothalamus following glucocorticoid treatment (24). Makino et al. (25) observed both positive and negative regulation of rat amygdalar CRF mRNA by glucocorticoids in vivo, dependent on the doses utilized and the time course of administration. On the other hand, Beyer et al. (26) demonstrated that adrenalectomy does not alter the expression of CRF in the amygdala. Although dexamethasone did not alter CRF levels in our previous studies with primary amygdalar cultures, we found here that dexamethasone will alter levels of the CRF-BP intracellularly. This provides a potential mechanism by which steroids can regulate CRF indirectly through actions on its binding protein.

The positive regulatory effect of dexamethasone on CRF-BP in the pituitary is consistent with what we have observed in primary amygdalar cultures. In vivo, glucocorticoids positively regulate CRF-BP expression in the pituitary (10). This is based on the finding that adrenalectomy will decrease rat pituitary CRF-BP expression. Other signal transduction pathways regulating CRF-BP expression in the pituitary have not yet been investigated.

The rat CRF-BP gene is known to contain CRE and AP-1 sites (18). AP-1 sites have been located at basepairs - 177 to $-171,-196$ to -190 and from -238 to -232 . It is likely that one or more of these sites mediate the TPA effect observable in our studies. Likewise the CRE at -127 to -123 likely accounts for the forskolin effect in our experiments. No consensus glucocorticoid response element (GRE) sequence is present in the 700 base pairs $5^{\prime}$ to the CRF-BP transcript start site. However, a GRE could be present further upstream and still be contained in the 3500 BP-CAT construct. Alternatively, protein-protein interactions or other mechanisms may modulate the positive effects of dexamethasone on the CRF-BP gene.

Of particular interest is the molecular mechanism of CRF actions on the CRF-BP gene. Previous studies utilising transient transfection assays in cell lines have demonstrated that deletion of the CRE element will abolish the effects that CRF has on the CRF-BP gene (18). This presumed action through PKA signalling pathways is consistent with the ability of CRF to increase cAMP levels through its interactions with its receptor (1).

The functional role that IL6 plays in stimulating CRF-BP is not known. The IL6 receptor mRNA has not been localized to the amygdala by in-situ hybridization although it is present in other neural regions (27). It is possible that IL6 may act through a subtype of the receptor that was not detected in the localization studies or it is possible that the amygdala may not express IL6 receptors in the basal state. However with inflammation, the receptor may be induced in the amygdala. Tissue injury and inflammation is known to be able to induce expression of the IL6 receptor in neural tissue
(28). To what extent our cell dispersion procedure promotes a biological situation similar to inflammation or injury is unclear.

It is not clear which response elements in the CRF-BP gene could modulate the IL6 response. There are NF-kB sites in the CRF-BP gene which could facilitate the actions of other interleukins. However, IL6 is known to act via the JAK/STAT signalling pathway (29). Most of the STAT proteins except for STAT6 bind to a consensus sequence consisting of 5'-TTCxxxGAA-3'; for STAT6 the binding element is $5^{\prime}$-TTCxxxxGAA-3' (30). There are no consensus response elements for any of the STAT proteins in the 700 base pairs $5^{\prime}$ to the CRF-BP transcript start site. However, for STAT6, there is one region, i.e. from -481 to -472 , in which five out of the six consensus base pairs can be found. Likewise, for the other STAT binding elements, there are two regions which contain five out of the required six base pairs. One of these is located from -201 to -193 and another is located from -481 to -473 . It is possible that these regions interact with STAT proteins to alter CRF-BP gene expression. Alternatively, consensus STAT binding elements which transduce the actions of IL6 could also be present further upstream.

Increased understanding of the mechanisms regulating CRF-BP expression in the amygdala is important because of the implied link between CRF expression and CRF-BP as coregulators and their potential role in the behavioural manifestations of stress. The studies in this report demonstrate that amygdalar CRF-BP appears to be positively regulated by a variety of stimuli-the cytokine IL6, activators of the PKA and PKC intracellular pathway, dexamethasone and, more importantly CRF. The elucidation of these signal transduction mechanisms are likely to be important in understanding the molecular basis of stress related behavioural alterations in the amygdala such as those involving anxiety or fear and even possibly depressive and anxiety disorders.

\section{Acknowledgements}

Dr Kasckow was supported by a NARSAD Young Investigator's Award, a Research Career Award (K01 NIMH001545-01) and a VA Merit Review Entry Program Award. Dr Seasholtz was supported by NIH DK42730.

\section{Accepted 2 July 1999}

\section{References}

1 Vale WW, Vaughan J, Perrin M. Corticotropin-releasing factor (CRF) family of ligands and their receptors. Endocrinologist 1997; 7: 3S-9S

2 Owens M, Nemeroff CB. Physiology and pharmacology of corticotropinreleasing factor Pharmacol Rev 1991; 43: 425-473.

3 Gray TS. The organization and possible function of amygdaloid corticotropin-releasing factor pathways. In: DeSouza EB, Nemeroff CB, eds. Corticotropin-Releasing Factor: Basic and Clinical Studies of a Neuropeptide. Boca Raton: CRC Press, 1990: 53-68.

4 Heinrichs SC, Pich EM, Miczek K, Britton KT, Koob GF. Corticotropinreleasing factor antagonist reduces emotionality in socially defeated rats via direct neurotropic action. Brain Res 1992; 581: 190-197.

5 Behan DP, Linton EA, Lowry PJ. Isolation of the human plasma corticotropin-releasing factor-binding protein. J Endocrinol 1989; 122: $23-31$.

6 Orth DN, Mount CD. Specific high-affinity binding protein for human 
corticotropin-releasing hormone in normal human plasma. Biochem Biophy Res Commun 1987; 143: 411-417.

7 Cortright DN, Nicoletti A, Seasholtz AF. Molecular and biochemical characterization of the mouse brain $\mathrm{CRH}$-binding protein. Mol Cell Endocrinol 1995; 111: 147-157.

8 Potter E, Behan DP, Fischer WH, Linton EA, Lowry PJ, Vale WW. Cloning and characterization of the cDNAs for human and rat corticotropin-releasing factor-binding proteins. Nature 1991; 349: 423-426.

9 Potter E, Behan DP, Linton EA, Lowry PJ, Sawchenko PE, Vale WW. The central distribution of corticotropin-releasing factor (CRF)-binding protein predicts multiple sites and modes of interaction with CRF. Proceed Natl Acad Sci USA 1992; 89: 4192-4196.

10 McClennan SJ, Cortright DN, Seasholtz AF. Regulation of pituitary corticotropin-releasing hormone-binding protein messenger ribonucleic acid levels by restraint stress and adrenalectomy. Endocrinology 1998; 139: 4435-4441.

11 Brouard A, Pelaprat D, Dana C, Vial M, Lhiaubet AM, Rostene W. Mesencephalic dopaminergic neurons in primary cultures express functional neurotensin receptors. J Neurosci 1992; 12: 1409-1415.

12 Cratty MS, Birkle DL. Depolarization-induced release of corticotropinreleasing factor (CRF) in primary neuronal cultures of the amygdala. Neuropeptides 1994; 26: 113-121.

13 Kasckow JW, Regmi Gill PS, Parkes DG, Geracioti TD. Regulation of corticotropin-releasing factor (CRF) messenger RNA and CRF peptide in the amygdala: studies in primary amygdalar cultures. Endocrinology 1997; 138: 4774-4792.

14 Greene LA, Rein G. Synthesis, storage and release of norepinephrine. Nature 1977; 268: 349-351.

15 Vale W, Vaughan J, Yamamoto G, Bruhn T, Douglas C, Dalton D, Rivier C, Rivier J. Assay of corticotropin-releasing factor. In: Conn PM, ed. Methods Enzymology. New York: Academic Press, 1983: 565-577.

16 Sambrook J, Fritsch EF, Maniatis T, Molecular Cloning. A Laboratory Manual. Cold Spring Harbor, NY: Cold Spring Harbor Laboratory Press, 1989: 7.43-7.52.

17 Maciejewski D, Crowe PD, DeSouza EB, Behan DP. Regulation of corticotropin-releasing factor-binding protein expression in cultured rat astrocytes. J Pharmacol Exp Ther 1996; 278: 455-461.

18 Cortright SN, Goosens KA, Lesh JS, Seasholtz AF. Isolation and characterization of the rat corticotropin-releasing hormone-binding pro- tein gene: transcriptional regulation by cyclic adenosine monophosphate CRH. Endocrinol 1997; 138: 2098-2108.

19 Mulchahey JJ, Regmi A, Sheriff S, Balasubramaniam A, Kasckow JW. Coordinate and divergent regulation of corticotropin-releasing factor (CRF) and CRF-binding protein expression in an immortalized amygdalar neuronal cell line. Endocrinology 1999; 140: 251-259.

20 Hernandez J, Hidalgo J. Endotoxin and intracerebroventricular injection of IL-1 and IL-6 induce rat brain metallothionein-I and -II. Neurochem Int 1998; 32: 369-373.

21 Wang J, Dunn AJ. Mouse interleukin-6 stimulates the HPA axis and increases brain tryptophan and serotonin metabolism. Neurochem Int 1998; 33: 143-154.

22 Stoecklin E, Wissler M, Gouillieux F, Groner B. Functional interactions between STAT5 and the glucocorticoid receptor. Nature 1996; 383: 726-728.

23 Mui AL, Wakao H, Kinoshita T, Kitamura T, Miyajima A. Suppression of interleukin-3-induced gene expression by a C-terminal truncated Stat5: role of Stat5 in proliferation. EMBO J 1996; 15: 2425-2433.

24 Hu S-B, Tannahill LA, Biswas S, Lightman SL. Release of corticotropinreleasing factor-41, arginine vasopressin and oxytocin from rat fetal hypothalamic cells in culture: response to activation of second messengers and to corticosteroids. J Endocrinol 1991; 132: 57-65.

25 Makino S, Gold PW, Schulkin J. Corticosterone effects on corticotropinreleasing hormone mRNA in the central nucleus of the amygdala and the parvocellular region of the paraventricular nucleus of the hypothalamus. Brain Res 1994; 640: 105-112.

26 Beyer HS, Matta SG, Sharp BM. Regulation of the messenger ribonucleic acid for corticotropin-releasing factor in the paraventricular nucleus and other brain sites of the rat. Endocrinology 1988; 123: 2117-2123.

27 Schobitz B, Van Den Dobbelsteen Holsboer F, Sutanto W, De Kloet WE. Regulation of interleukin 6 gene expression in rat. Endocrinology 1993; 132: 1569-1576.

28 Schobitz B, de Kloet ER, Holsboer F. Gene expression and function of interleukin 1, interleukin 6, and tumor necrosis factor in the brain. Prog Neurobiol 1994; 44: 397-432.

29 Briscoe J, Kohllhuber F, Muller M. JAKs and STATs branch out. Trends Cell Biol 1996; 6: 336-340.

30 Mikita T, Campbell D, Wu P, Williamson K, Schindler U. Requirements for interleukin-4 induced gene expression and functional characterization of stat6. Mol Cell Biol 1995; 16: 5811-5820. 